Glaucoma Unit, Moorfields Eye Hospital, London L Fontana

R Armas

D F Garway-Heath

D Poinoosawmy

R A Hitchings

Department of Cardiovascular and Respiratory Sciences, University "La

Sapienza", Rome, Italy L Fontana

Glaxo Department of Ophthalmic Epidemiology, Moorfields Eye Hospital, London C V Bunce

Correspondence to: Roger A Hitchings, Glaucoma Unit, Moorfield Eye Hospital, City Road, London EC1V 2PD.

Accepted for publication 11 May 1999

\title{
Clinical factors influencing the visual prognosis of the fellow eyes of normal tension glaucoma patients with unilateral field loss
}

\author{
Luigi Fontana, Rodolfo Armas, David F Garway-Heath, Catey V Bunce, \\ Darmalingum Poinoosawmy, Roger A Hitchings
}

\begin{abstract}
Aim-To investigate the influence of several clinical variables on the development of visual field loss in the "second eye" of patients with normal tension glaucoma (NTG) presenting with unilateral field loss.

Methods-Patients with NTG and unilateral field loss at presentation were selected from a cohort of 403 consecutive diagnoses of NTG. The state of the visual field "normal" or with a visual field defect was defined using the Advanced Glaucoma Intervention Study (AGIS) template. Where available, optic disc planimetry was carried out on stereo photographs taken at presentation. Measurements of the topography of each of these optic discs were compared with morphometric values from a group of normal subjects, allowing for differences in age and disc size. For each patient the percentage of the relative neuroretinal rim (NRR) area was calculated. The time taken to develop a visual field defect was related to clinical factors including age, sex, peak and mean diurnal intraocular pressure (IOP), refraction, relative NRR area, and the AGIS score of the fellow eye at presentation

Results-54 patients were included in the study. The median (range) follow up time was 49.2 (11.1-116.7) months. 14 (26\%) patients developed field loss in the eyes with an initially normal field. The estimate of the median time to field loss onset was 95.1 months. Field damage developed more rapidly in women and in patients with greater AGIS score in the contralateral eye at the beginning of follow up ((adjusted hazard ratio, HR (95\% confidence interval, CI) $0.20(0.04 ; 0.93) ; 1.19$ $(1.02 ; 1.41)$ respectively)). Little evidence of any association was found between time to onset of field loss and each of age, refraction, and peak or mean diurnal IOP. Planimetric disc analysis was carried out in $33(61 \%)$ patients. Of these $10(30 \%)$ developed field loss in the eyes with initial normal field at a median follow up of $\mathbf{9 5 . 1}$ months. After adjustment for sex and
\end{abstract}

AGIS, relative NRR area was found to be significantly related to the time of onset of field damage, the greater the reduction in relative NRR area, the shorter the time to visual field loss (HR 0.93 (0.89; 0.99)).

Conclusions-NTG patients with unilateral field loss are at high risk of developing field damage in the eyes with an initially normal visual field. In this study, the visual prognosis of the eye with the normal visual field at presentation was found to be influenced by the extent of the reduction in relative NRR area together with the severity of field damage in the contralateral eye at presentation. (Br f Ophthalmol 1999;83:1002-1005)

Normal tension glaucoma (NTG) is a subset of primary open angle glaucoma (POAG), with characteristic glaucomatous cupping and field loss, an open drainage angle, and an intraocular pressure (IOP) consistently within the normal range. ${ }^{1}$ Patients with POAG frequently present with bilateral field loss at diagnosis. However, in the early stage of the disease visual field loss may be found in only one eye. ${ }^{2}$ Previous studies investigating the visual prognosis of fellow eyes of POAG patients with unilateral field loss have shown a much higher incidence of development of field loss in these patients than in ocular hypertensives. ${ }^{3-5}$ Therefore, POAG patients with uniocular field loss represent an ideal population in which to investigate factors influencing the onset of field loss over a period of time.

In a retrospective longitudinal study we investigated the influence of several clinical variables on the temporal relation between time of presentation and onset of white on white perimetric defects in the fellow eyes of a group of NTG patients with unilateral field loss.

Materials and methods

The hospital records of all patients $(n=403)$ diagnosed with NTG at Moorfields Eye Hospital between 1986 and 1996 were retrospectively analysed. To make the diagnosis of NTG, patients must have had an untreated IOP $\leqslant 21 \mathrm{~mm} \mathrm{Hg}$ on diurnal phasing (at least 
eight readings, allowing a single IOP reading not more than $23 \mathrm{~mm} \mathrm{Hg}$ ), a reproducible visual field defect typical of glaucoma (of retinal nerve fibre layer type), glaucomatous optic nerve head cupping (in the eye with field loss) and open drainage angles on clinical examination. Patients with a normal visual field in one eye and a field defect in the contralateral eye, at the time of diagnosis, were selected for this study. Visual field testing was carried out using the 24-2 Humphrey field analyser (HFA) (Humphrey Instruments Inc, Palo Alto, CA, USA) field test. A normal visual field was defined using STATPAC-2 software (Humphrey Instruments Inc, Palo Alto, CA, USA) and the Advanced Glaucoma Intervention Study (AGIS) template. ${ }^{6}$ In brief, the AGIS visual field score, which ranges from 0 (no defect) to 20 (all test sites deeply depressed) is based on the number and depth of adjacent depressed test locations present in a single field test. The visual fields were scored by hand, using transparent plastic scoring templates placed over the total deviation printout of the threshold program, single field test, STATPAC- 2 analysis and highlighting any defective test location. In this study, a normal visual field was defined as no defective locations, according to the AGIS template, at the first three consecutive fields at the diagnosis. The onset of visual field loss was defined as the development of one or more defective same site locations in at least three consecutive field tests. The time to onset of field loss was determined as the interval between the date of diagnosis and the first defective visual field. The AGIS method of scoring field defects was used to assess the severity of field loss in the contralateral eye with field damage at the diagnosis. For each patient, the AGIS score of the first field (at presentation) and the mean and peak values of the diurnal IOP curve were recorded. In addition, each patient had to have a visual acuity of $6 / 18$ or better throughout follow up and absence of concomitant ophthalmic disease.

Where available, optic disc photographs taken at the time of first presentation were reviewed. These photographs had been taken, after mydriasis, with a Canon CF-60U retinal fundus camera, using a 30 degree angle view and a 35 $\mathrm{mm}$ Kodak Ektachrome EPR 150 film. Sequential photographs of each eye were taken with a lateral shift in camera position to obtain a stereo effect. Optic disc analysis (planimetry) was carried out by one observer (LF), masked to the patient's follow up, using a computerised image analysis system (Thot Informatique, $\mathrm{Pr} \mathrm{Be}-$ chetoille, Angers, France). This system has been shown to provide reproducible measurements of the optic nerve head. ${ }^{7}$ The disc edge was interactively defined as the inner edge of the peripapillary scleral ring, the optic cup was outlined following contour and not pallor. For each patient, the relative neuroretinal rim (NRR) at the time of diagnosis was estimated by comparison of the measured NRR with data derived from measurements of 88 normal subjects, allowing for differences in age and disc size. ${ }^{8}$
It was possible to quantify the area of the NRR with reference to this normal population. The NRR is related to the size of the optic $\operatorname{disc}^{8-12}$ and the age of the subject ${ }^{13}$ and thus may be expressed as the percentage of that expected, given the optic disc size and age of the subject. This measurement we defined as the relative neuroretinal rim area (relative NRR area).

The proportion of patients developing field loss in the initially "normal" eye was found using survival analysis. For those patients who developed field loss during the course of the study, the follow up period was ended at the date of onset. Cox regression analysis (proportional hazards regression analysis) was used to investigate the influence of various clinical variables on the risk of development of field loss. Factors analysed included age, sex, peak and mean diurnal IOP, refraction, relative NRR area, and the AGIS score of the fellow eye at presentation. Each factor was entered in the model separately. Factors were first fitted in a univariate model, then all those significant at $\mathrm{p}<0.05$ were fitted in a multivariate model to assess independence of effects. All analyses were conducted using sPSs for Windows (software version 7.0), taking $p<0.05$ to be statistically significant.

\section{Results}

Of the patients whose records were reviewed, 54 fulfilled the inclusion criteria for this study. Thirty four patients $(63 \%)$ were women. The median (interquartile range, IQR) age at presentation was $62.6(56.2 ; 67)$ and 60.3 (52.6; 69.6) years for men and women respectively. The median (IQR) peak and mean diurnal IOP of the eyes with normal visual field at diagnosis were $19(18 ; 20) \mathrm{mm} \mathrm{Hg}$ and 16.1 (14.6; 17.8) $\mathrm{mm} \mathrm{Hg}$. The median (IQR) refractive error was $0(-0.96 ; 1.84)$ dioptres. Patients had been followed at regular intervals with visual field testing every 4-6 months. None of the patients was lost to follow up. The median (IQR) number of field tests for each patient was $9.5(6 ; 18.2)$, for a total number of 657 visual fields analysed in this study. The median (IQR) of the descriptive visual field indices mean defect (MD) and corrected pattern standard deviation (CPSD) for the eyes with normal field and their contralateral with field loss at diagnosis were $-1.05(-1.67$;

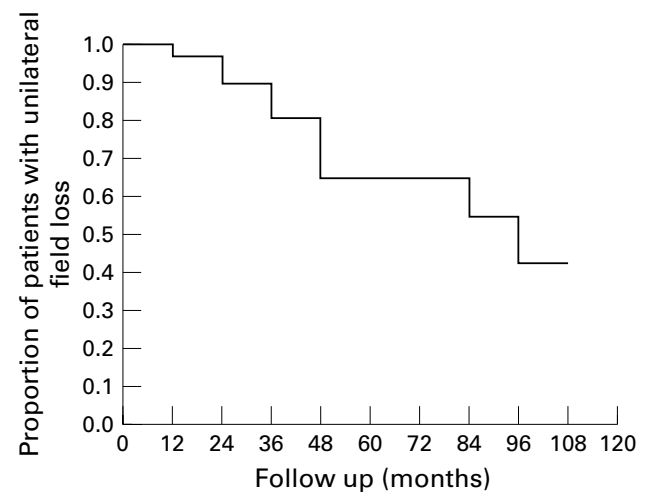

Figure 1 Survival analysis. Development of visual field loss in the normal field eyes of patients with normal tension glaucoma $(n=54)$ with unilateral field loss with follow up. 
Table 1 Proportional hazards regression analysis. Univariate and multivariate estimate hazards. Independent variables age, peak and mean diurnal IOP, AGIS, and refraction were introduced as continuous

\begin{tabular}{lllll}
\hline & $\begin{array}{l}\text { Unadjusted } \\
\text { estimated } \\
\text { hazard }\end{array}$ & $\begin{array}{l}\text { Unadjusted } \\
95 \% \mathrm{CI}\end{array}$ & $\begin{array}{l}\text { Adjusted } \\
\text { estimated } \\
\text { hazard }\end{array}$ & $\begin{array}{c}\text { Adjusted } \\
95 \% \mathrm{CI}\end{array}$ \\
\hline Age & 1.011 & $0.955 ; 1.071$ & - & - \\
Sex & $0.203^{\star}$ & $0.045 ; 0.923$ & $0.201^{\star}$ & $0.043 ; 0.933$ \\
Peak IOP & 0.95 & $0.86 ; 1.04$ & & - \\
Mean IOP & 1.083 & $0.875 ; 1.342$ & - & - \\
Refraction & 1.105 & $0.845 ; 1.445$ & - & $1.018 ; 1.412$ \\
AGIS fellow eye & $1.217^{\star}$ & $1.022 ; 1.449$ & $1.199^{\star}$ & 1.04 \\
\hline
\end{tabular}

Sex was analysed as categorical variable, $0=$ female and $1=$ male.

${ }^{\star} \mathrm{p}<0.05$.

Table 2 Optic disc morphometric characteristics, of patients who developed field loss (column 1) and of those who retained a normal field in the eye with initially normal field (column 2), during the follow up. Data are presented as median (IQR)

\begin{tabular}{lll}
\hline & 1 & 2 \\
\hline Disc area $\left(\mathrm{mm}^{2}\right)$ & $2.26(1.98 ; 2.76)$ & $2.04(1.82 ; 2.42)$ \\
Rim area $\left(\mathrm{mm}^{2}\right)$ & $0.91(0.77 ; 1.06)$ & $1.10(0.91 ; 1.15)$ \\
Cup/disc area & $0.61(0.52 ; 0.64)$ & $0.47(0.43 ; 0.53)$ \\
Relative NRR area $(\%)$ & $57.3(52 ; 60)$ & $71.6(61.6 ; 76.9)$ \\
\hline
\end{tabular}

$-0.11) \mathrm{dB}, 1.42(0.83 ; 2.14)$ and -7.51 $(-10.99 ;-4.46) \quad \mathrm{dB}, 9.70 \quad(4.98 ; 11.94)$ respectively. For the eyes with initial field loss the median (IQR) of calculated AGIS score of the first visual field was $5(3 ; 8.25)$.

The median (range) follow up was 49.2 (11.1-116.7) months. During this period, 14 $(26 \%)$ patients developed visual field loss in the eye with initially normal field, of whom 12 $(85 \%)$ patients were women. The onset of field loss, during follow up, was analysed by survival analysis (Kaplan-Meier survival curve) (Fig 1). The median time to field loss onset was 95.1 months. Analysis using Cox univariate and multivariate regression techniques revealed strong evidence of independent associations between time to onset of field loss and both the sex of the patient and the severity of field loss of the fellow eye (AGIS score) at presentation (Table 1). The results provide little evidence of any association between time to onset of field damage and age, refraction, and IOP (peak and mean).

Optic disc photographs of 37 (68\%) patients were available for morphometric analysis. For each patient the relative NRR area was calculated. Four patients were excluded because the optic disc area was outside the range of values found in the normal database. For the 33 patients remaining, the median (range) follow up was $44.6(11.1-116.7)$ months. During this period, $10(30 \%)$ patients developed visual field loss in the eye with initially normal field at a median follow up of 95.1 months. The morphometric characteristics of the optic discs are summarised in Table 2. After adjustment for sex and AGIS score, the relative NRR area at presentation was found to be significantly

Table 3 Proportional hazards regression analysis. Univariate and multivariate estimate hazards. Independent variable relative NRR was introduced as continuous

\begin{tabular}{lllll}
\hline & $\begin{array}{l}\text { Unadjusted } \\
\text { estimated } \\
\text { hazard }\end{array}$ & $\begin{array}{l}\text { Unadjusted } \\
95 \% \mathrm{CI}\end{array}$ & $\begin{array}{l}\text { Adjusted } \\
\text { estimated } \\
\text { hazard }\end{array}$ & $\begin{array}{l}\text { Adjusted } \\
95 \% \mathrm{CI}\end{array}$ \\
\hline Relative NRR area (\%) & $0.928^{\star}$ & $0.79 ; 0.979$ & $0.938^{\star}$ & $0.887 ; 0.992$ \\
\hline${ }^{\mathrm{p}}<0.05$. & & & &
\end{tabular}

related to the time to onset of field loss (Table 3). The risk of developing field loss was less in eyes with a larger relative NRR area.

\section{Discussion}

Patients with NTG may present with asymmetric field loss at the diagnosis. ${ }^{1}$ In these patients, field asymmetry has been shown to be related to unequal $\mathrm{IOP}^{1415}$ and ocular blood flow ${ }^{16}{ }^{17}$ between fellow eyes. With the course of time, NTG patients with unilateral field loss are likely to develop field loss in both eyes. ${ }^{18}$ In this study, we investigated the visual prognosis of fellow eyes of NTG patients with unilateral field loss.

It is important to mention that during the time span covered by this study, none of the patients received medical or surgical treatment for glaucoma to the eye with normal field. Furthermore, none of patients received treatment with systemic drugs such as calcium channel blockers that may influence the course of the disease. ${ }^{19}$ Eight patients received treatment to the contralateral eye with field loss at diagnosis, following evidence of progression of visual field loss during the follow up. Of these, five patients underwent fistulising surgery and three received medical treatment with topical $\beta$ blockers (betaxolol $0.5 \%$ twice daily). Although filtration surgery may alter the aqueous humour dynamics of the fellow unoperated eye $^{20}$ and uniocular application of topical $\beta$ blockers may reduce the IOP of the contralateral eye, ${ }^{21} 22$ we do not know whether treatment given to one eye may influence the natural course of the disease of the contralateral eye.

During a median follow up of 4.1 years, $26 \%$ of the patients developed white on white perimetric defects in the eye with initially normal field. This is comparable with the results of previous studies investigating the frequency of field loss development in fellow eyes of high tension glaucoma patients with unilateral field loss. $^{3-5}$ The proportion of patients developing field loss, reported in these studies, varied from 15 to $29 \%$ up to $43 \%$ during a follow up period of 5-7 years.

As the time to onset of field loss varies greatly between patients (Fig 1), it is important for the clinician to identify clinical factors that may be predictive of an early onset of field loss during the follow up. Our results strongly suggest that the prognosis of fellow eyes of NTG patients with unilateral field loss, is related to the sex of the patient, the severity of field loss of the contralateral eye, and the quantitative measurements of the optic nerve head at presentation. In our study, little evidence of any association was found between time to onset of field damage and each of age, refraction, and IOP (peak and mean diurnal values). NTG is known to affect women more frequently than men $^{1}$; however, a sex related difference in the rate of progression of NTG has not been previously reported in studies investigating field progression over time..$^{23-25}$ The limited number of patients in this study prohibits further analysis of this finding.

The natural history of NTG is for patients to develop field loss in both eyes. ${ }^{18}$ The time to 
development of a visual field defect in the "second eye" seems to be related to the severity of the defect in the "first eye". The more severe the defect the earlier visual field loss develops in the "second eye".

Planimetric disc measurements showed that compared with a group of normal subjects, taking into account age and disc size, most patients had at least $30-40 \%$ NRR loss in the eye with normal field at presentation. This finding confirms the presence of measurable changes of the optic nerve head in the normal field (white on white perimetry) eyes of POAG patients with unilateral field loss. ${ }^{26} 27$ Onset of field loss occurred more rapidly in patients with lower relative NRR area, corresponding to a greater cup/disc ratio. The maximum relative NRR found in patients who developed field loss during the time covered by this study was $67 \%$.

Given the retrospective nature of our analysis and the small number of patients investigated, our results must be interpreted with caution. However, this study provides a reasonable estimate of the prognosis of fellow eyes of untreated NTG patients with unilateral field loss as well as a useful method for the clinician to identify patients at greater risk of developing early field loss. In this way treatment to the eye with initially normal field, may be started at diagnosis, or delayed in relation to the likelihood of visual field defects being detectable during an appreciable period of follow up.

Each author states that he/she has no proprietary interest in the development or marketing of any product or instrument development or marketing
mentioned in this article.

Presented in part at the Association for Research in Vision and Ophthalmology meeting, Fort Lauderdale, FL, 11-16 May 1997.

1 Levene R. Low tension glaucoma. A critical review and new material. Surv Ophthalmol 1980;24:621-64.

2 Drance S, Wheeler C, Pattullo M. Uniocular open-angle glaucoma. Am ₹ Ophthalmol 1968;65:891-902.

3 Harbin TS, Podos SM, Kolker AE, et al. Visual field progression in open-angle glaucoma patients presenting with monocular field loss. Trans Am Acad Ophthalmol Otolaryngol 1976;81:253-7.

4 Kass MA, Kolker AE, Becker B. Prognostic factors in glaucomatous visual field loss. Arch Ophthalmol 1976;94:12746.

5 Susanna R, Drance SM, Douglas GR. The visual prognosis of the fellow eye in uniocular chronic open-angle glaucoma. Br f Ophthalmol 1978;62:327-9.
6 Advanced Glaucoma Intervention Study Investigators. Avanced Glaucoma Intervention Study Investigators. scoring and reliability. Ophthalmology 1994;101:1445-55.

7 Sturmer J, Poinooswamy D, Broadway DC, et al. Intra- and inter-observer variation of optic nerve head measurements in glaucoma suspects using disc-data. Int Ophthalmol 1992; 16:227-33.

8 Garway-Heath DF, Hitchings RA. Quantitative evaluation of the optic nerve head in early glaucoma. Br $\mathcal{F}$ Ophthalmol 1998;82:352-61.

9 Britton RJ, Drance SM, Schulzer M, et al. The area of the neuroretinal rim of the optic nerve in normal eyes. Am $\mathcal{f}$ Ophthalmol 1987;103:497-504.

10 Jonas JB, Gusek GC, Naumann GOH. Optic disc, cup and neuroretinal rim size configuration and correlation in normal eyes. Invest Ophthalmol Vis Sci 1988;29:1151-8.

11 Jonas JB, Gusek GC, Naumann GO. Optic disc morphometry in chronic primary open-angle glaucoma. I. Morphometric intrapapillary characteristics. Graefes Arch Clin Exp Ophthalmol 1988;226:522-30.

12 Caprioli J, Miller JM. Optic disc rim area is related to disc size in normal subjects. Arch Ophthalmol 1987;105:1683-5.

13 Garway-Heath DF, Hitchings RA. Aging changes of the optic nerve head in relation to open angle glaucoma. $\mathrm{Br} F$ Ophthalmol 1998:81:840-5.

14 Cartwright MJ, Anderson DR. Correlation of asymmetric damage with asymmetric intraocular pressure in normal tension glaucoma. Arch Ophthalmol 1988;106:898-900.

15 Crichton A, Drance SM, Gordon RD, et al. Unequal intraocular pressure and its relation to asymmetric visual field defects in low-tension glaucoma. Ophthalmology 1989; 96:1312-14.

16 Nicolela MT, Drance SM, Rankin SJA, et al. Color doppler imaging in patients with asymmetric glaucoma and unilateral field loss. Am f Ophthalmol 1996;121:502-10.

17 Fontana L, Poinooswamy D, Bunce CV, et al. Pulsatile ocular blood flow investigation in asymmetric normal tension glaucoma and normal subjects. Br f Ophthalmol 1998;82: glaucona $731-6$.

18 Poinoosawmy D, Fontana L, Wu J, et al. Asymmetric visual field defects in normal tension and high tension glaucoma. Ophthalmology 1998;105:988-91.

19 Bose S, Piltz JR, Breton ME. Nimodepine a centrally active calcium antagonist, exerts a beneficial effect on contrast sensitivity in patients with normal tension glaucoma and in control subjects. Ophthalmology 1995;102:1236-41.

20 Diestelhorst M, Krieglstein G. The effect of trabeculectomy on the aqueous humour flow of the unoperated fellow eye. Graefes Arch Clin Exp Ophthalmol 1991;229:274-6.

21 Kwito GM, Shin DH, Ahn BH, et al. Bilateral effects of long term monocular timolol therapy. Am f Ophthalmol 1987;104:591-4.

22 Martin XD, Rabineau PA. Intraocular pressure effects of timolol after unilateral instillation. Ophthalmology 1988;95: 1620-3.

23 Gliklich RE, Steinmann WC, Spaeth GL. Visual field change in low-tension glaucoma over a five-year follow-up. Ophthalmology 1989;96:316-20.

24 Noureddin, BN, Poinooswamy D, Fitzke FW, et al. Regression analysis of visual field progression in low tension glaucoma. Br f Ophthalmol 1991;75:493-5.

25 Araie M, Sekine M, Suzuki Y, et al. Factors contributing to the progression of visual field damage in eyes with normalthe progression of visual field damage in eyes with no
tension glaucoma. Ophthalmology 1994;101:1440-4.

26 Caprioli J, Miller JM, Sears M. Quantitative evaluation of the optic nerve head in patients with unilateral visual field loss from primary open-angle glaucoma. Ophthalmology 1987;94:1484-7.

27 Zeyen TG, Raymond M, Caprioli J. Disc and field damage in patients with unilateral visual field loss from primary open-angle glaucoma. Doc Ophthalmol 1992;82:279-86. 